\title{
ADSORPTION OF AMMONIUM IONS ONTO MULTI-WALLED CARBON NANOTUBES
}

\author{
HAMIDREZA SADEGH ${ }^{\mathrm{a},{ }^{*},}$, GOMAA A. M. ALI ${ }^{\mathrm{b}, \mathrm{c}}, \mathrm{ZEYNAB}$ ABBASI ${ }^{\mathrm{d}}$, \\ MALLIKARJUNA N. NADAGOUDA ${ }^{e}$
}

\begin{abstract}
Multi-walled carbon nanotubes (MWCNTs) surfaces have been characterized by FTIR and SEM techniques. The adsorption performance of MWCNTs was investigated for the removal of ammonium ions from wastewater. The effect of contact time, temperature and initial ions concentration on the adsorption of ammonium ions by MWCNTs were studied and optimized. The results showed a high adsorption capacity of $129 \mathrm{mg} / \mathrm{g}$ according to Langmuir isotherm model and removal efficiency of $95 \%$. In addition, the adsorption kinetic and equilibrium data were fitted to the pseudo-second-order model. The potential application of MWCNTs for adsorption of ammonium ions from wastewater was successfully accomplished using a batch adsorption technique.
\end{abstract}

Keywords: Carbon nanotubes; Removal; Adsorption; Kinetics; Isotherm; Ammonium ions; Langmuir

\section{INTRODUCTION}

The scientific community has a growing interest in environmental protection against aquatic pollution from various industrial activities for the reduction and/or the valorization of solid wastes. In this context, many studies were performed using nanoadsorbents. These adsorbents are used for removal and adsorption of ammonium ions from wastewater [1, 2]. The use of these

\footnotetext{
a West Pomeranian University of Technology, Szczecin; Faculty of Chemical Technology and Engineering; Institute of Inorganic Chemical Technology and Environment Engineering; ul. Pułaskiego 10, 70 - 322 Szczecin, Poland

b Chemistry Department, Faculty of Science, Al-Azhar University, Assiut, 71524, Egypt

c Faculty of Industrial Sciences and Technology, Universiti Malaysia Pahang, Gambang, 26300, Kuantan, Malaysia

d Department of Chemistry, Science and Research Branch, Islamic Azad University, Tehran, Iran

e Department of Mechanical and Materials Engineering, Wright State University, Dayton, USA

*Corresponding author: hamidreza.sadegh@srbiau.ac.ir, h.sadegh@chemist.com
} 
nanomaterials has shown many advantages, such as large specific surface area, effective and economical removal, high adsorption capacity, and surface reactivity [3-7].

Carbon nanotubes (CNTs), which were discovered by lijima in 1991 [8], are one of the most widely studied carbon nanomaterials and can serve as excellent adsorbents [9-11] because of their hollow and layered structure and large specific surface area, which make CNTs the most commonly used nanomaterials for adsorbing toxic material [12]. CNTs can be classified into three types: single-walled (SWCNTs), multi-walled (MWCNTs), and functionalized (f-CNTs) [12-15]. Such materials have already played a key role in the effective removal of several organic contaminants from water [16]. For example, MWCNTs are much more effective in the removal of organic chemicals from wastewater than activated carbon $[17,18]$.

The aim of the present work is to evaluate the potential and effectiveness of MWCNTs for the removal of ammonium ions from wastewater. The effect of various parameters such as contact time (t), temperature $(T)$, and initial ions concentration $(C)$ on the adsorption process were studied and optimized. The objects of this work are as follows: (i) to study the feasibility of using MWCNTs as adsorbents for the removal of ammonium ions, (ii) to determine the applicability of various isotherm models (i.e., Langmuir and Freundlich) to find the best-fit isotherm equation, and (iii) to evaluate kinetic parameters and explain the nature of adsorption.

\section{RESULTS AND DISCUSSION}

FTIR was used to characterize the functional groups present on the surface of the adsorbent. Figure 1 (a) showed a weak band at $3785 \mathrm{~cm}^{-1}$ which indicate the presence of unbound or free hydroxyl group $(-\mathrm{OH})$ [19]. The strong band at $3445 \mathrm{~cm}^{-1}$ might be due to the presence of intermolecular hydrogen bonding or $\mathrm{O}-\mathrm{H}$ stretching vibrations of the carboxylic acid groups $[19,20]$. The band at $1720 \mathrm{~cm}^{-1}$ can be assigned to the $\mathrm{C}=\mathrm{O}$ stretching mode of the $-\mathrm{COOH}$ groups [21]. The band at $1570 \mathrm{~cm}^{-1}$ can be assigned to the $C=C$ stretching, which indicates the graphite structure of MWCNTs [20]. The bands at 1120 and $900 \mathrm{~cm}^{-1}$ can be assigned to the $\mathrm{C}-\mathrm{O}$ and $\mathrm{C}-\mathrm{C}$ stretching modes, respectively [19, 22].

In addition, the surface textural and morphological properties of the developed adsorbent were carried out using SEM imaging, as shown in Figure 1 (b). MWCNTs were entangled and some were in the form of agglomerates with various bunches of rope-like structures with smooth surfaces. The tube lengths were several micrometers while the diameters were lower than $50 \mathrm{~nm}$. 

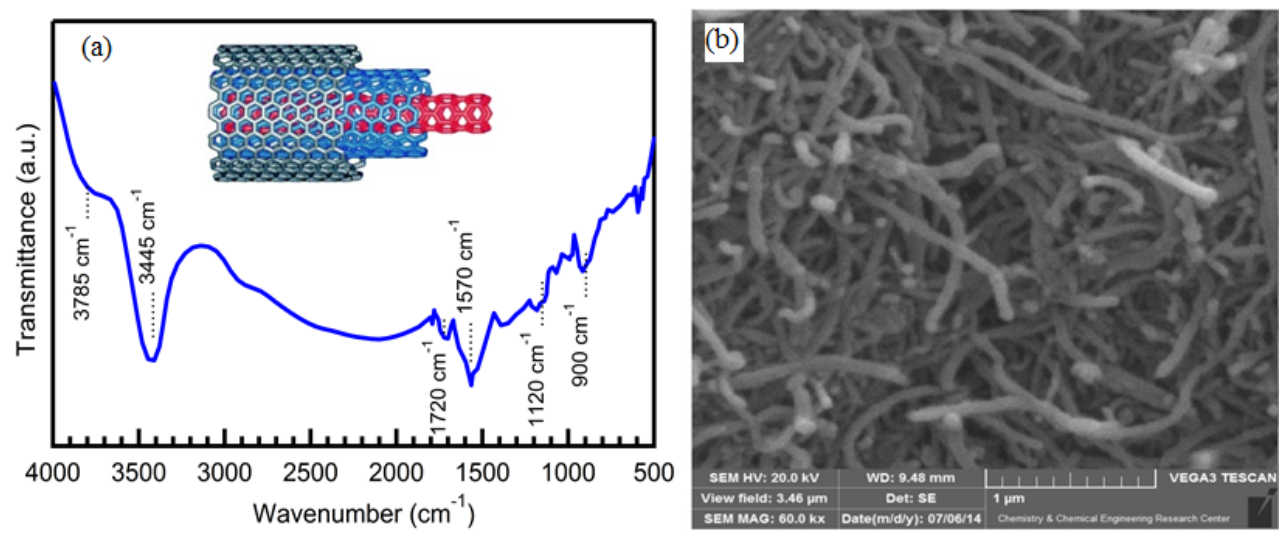

Figure 1. FTIR spectrum through graphical representation (a) and SEM image (b) of MWCNTs.

In this work, the adsorption capacity of ammonium ions on MWCNTs surface was studied. Effect of contact time at adsorption experiments occurred at various time between 10 and $100 \mathrm{~min}$. As shown in Figure 2, removal of ammonium ions by MWCNTs adsorbent was very slow after 55 $\mathrm{min}$; therefore, $60 \mathrm{~min}$ was selected as the optimum time for the adsorption process of ammonium ions on MWCNTs surface at $\mathrm{pH}=6$ and $\mathrm{T}=298 \mathrm{~K}$.

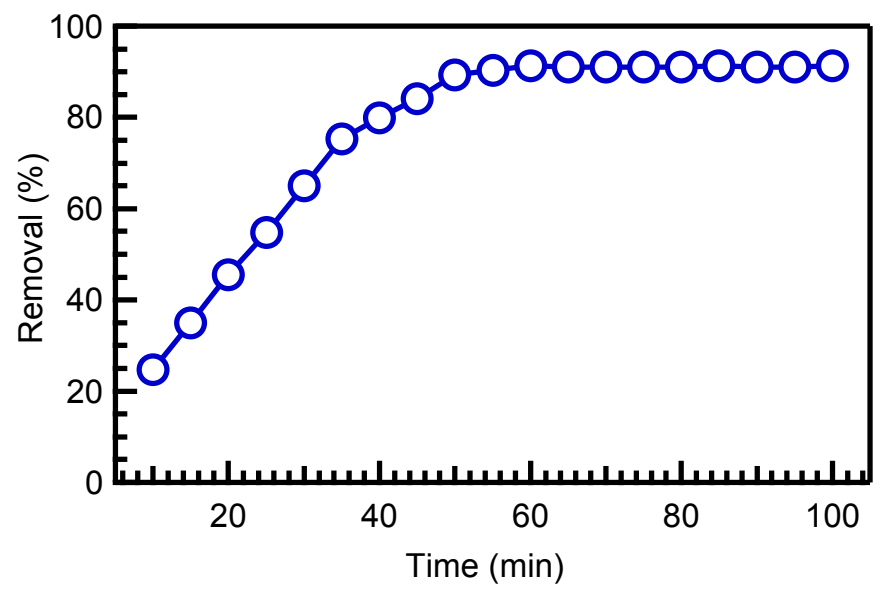

Figure 2. Effect of contact time on the removal of ammonium ions by MWCNTs (at $\mathrm{pH}=6, \mathrm{~T}=298 \mathrm{~K}, \mathrm{C}_{\mathrm{o}}=140 \mathrm{mg} / \mathrm{L}$, dosage $=0.05 \mathrm{~g}$ and $10 \mathrm{~mL}$ solution). 
To study the effect of temperature on ammonium ions removal on MWCNTs surface, adsorption experiments were carried out at several temperatures ranging from 298 to $338 \mathrm{~K}$. All adsorption experiments were performed at $60 \mathrm{~min}$ and at a $\mathrm{pH}$ of 6 . Figure 3 displays the effect of temperature on the removal of ammonium ions by MWCNTs adsorbents. The removal of ammonium ions on MWCNTs surface increased with increasing the temperature; removal was $75 \%$ at $298 \mathrm{~K}$ and reached $93 \%$ at $338 \mathrm{~K}$.

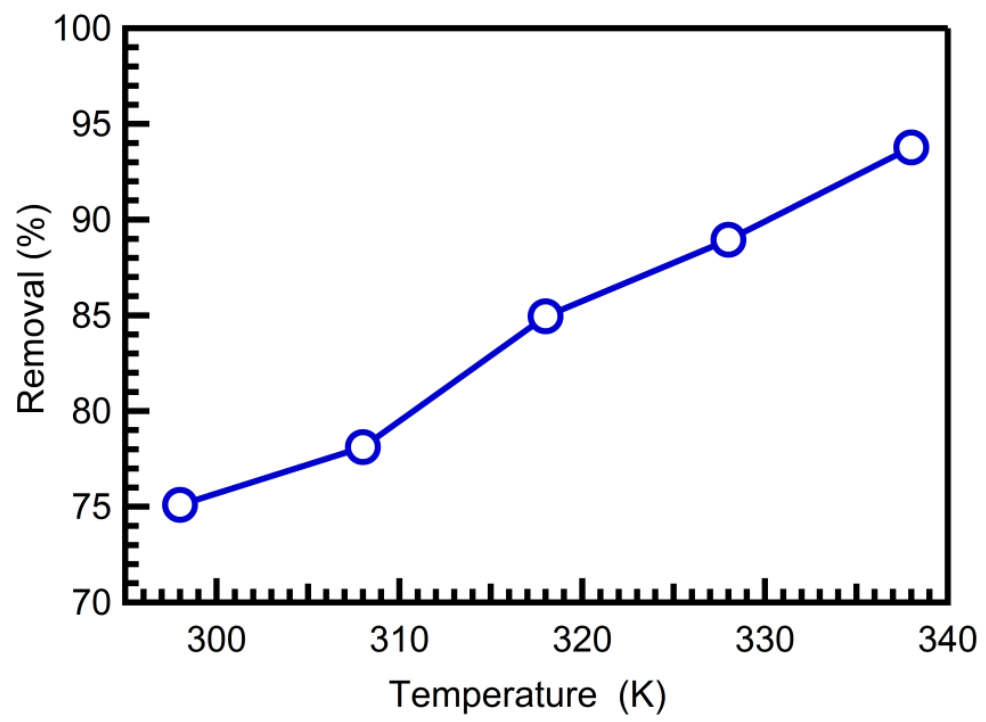

Figure 3. Effect of temperature on the removal of ammonium ions by MWCNTs (at $\mathrm{pH}=6$, time $=60 \mathrm{~min}, \mathrm{C}_{\circ}=140 \mathrm{mg} / \mathrm{L}$, dosage $=0.05 \mathrm{~g}$ and $10 \mathrm{~mL}$ solution).

The effect of initial ammonium ion concentrations on the adsorption by MWCNTs surface is shown in Figure 4. The percentage of adsorbed ions increased with the increase in initial ion concentration. Around $60 \%$ of ammonium ions were removed using $80 \mathrm{mg} / \mathrm{L}$ MWCNTs, while at $140 \mathrm{mg} / \mathrm{L}$ more than $93 \%$ of the ions were been removed. This is because at higher concentrations, the ratio of the initial number of ammonium ions to the available surface area is high and, subsequently, the fractional adsorption becomes independent on the initial concentration. However, at high concentrations, the available sites for adsorption become wider and the adsorption of ions depends upon the concentration [23]. 


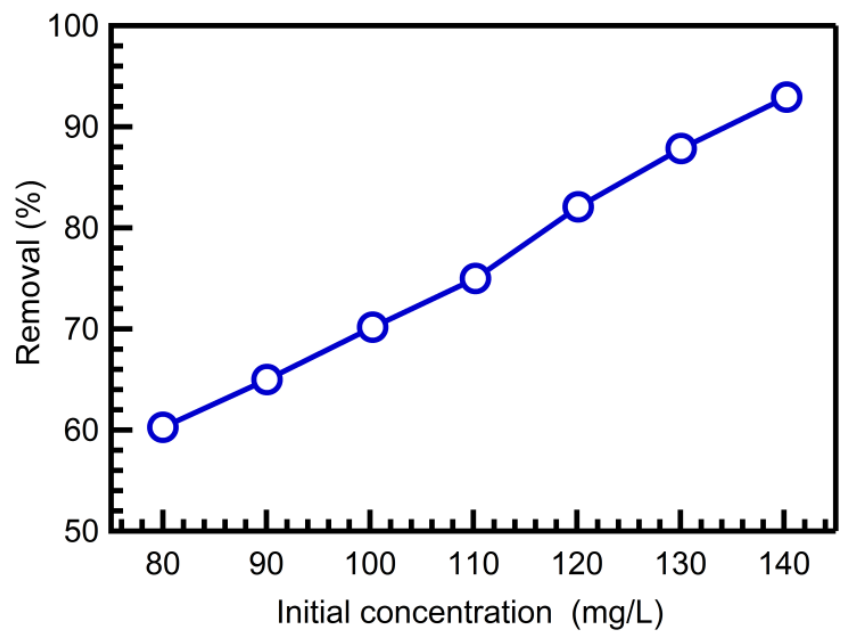

Figure 4. Effect of initial ions concentration on the removal of ammonium ions by MWCNTs (at $\mathrm{pH}=6$, time $=60 \mathrm{~min}$, $\mathrm{T}=298 \mathrm{~K}$, dosage $=0.05 \mathrm{~g}$, and $10 \mathrm{~mL}$ solution).

Adsorption is a physicochemical process that involves mass transfer of a solute from liquid phases to the adsorbent surface. Four of the most widely used kinetic models, pseudo-first-order, pseudo-second-order, intraparticle diffusion, and Elovich models, were used to study the adsorption kinetic behavior of ammonium ions onto MWCNTs. The best-fit model was selected based on the linear regression correlation coefficient values $\left(R^{2}\right)$ and the average relative error (ARE). The differential form of the pseudo-firstorder kinetic equation $[24,25]$ can be expressed as:

$$
\frac{d q_{t}}{d_{t}}=k_{f}\left(q_{e}-q_{t}\right)
$$

where $q_{e}$ and $q_{t}$ are the amounts of dye per unit of adsorbent $(\mathrm{mg} / \mathrm{g})$ at time $t$, respectively; $k_{f}$ is the pseudo-first rate constant $\left(\mathrm{min}^{-1}\right) ; t$ is the contact time between the adsorbent and adsorbate ( $\mathrm{min})$. Integrating equation (1) and using boundary condition, $t=0$ to $t=t$ and $q_{t}=0$ to $q_{t}=q_{t}$, the next linear form will be obtained, known as a first order Lagergren's rate equation [23]:

$$
\log \left(q_{e}-q_{t}\right)=\log q_{e}-\frac{k_{f}}{2.303} t
$$


A linear fit of $\log \left(\mathrm{q}_{\mathrm{e}}-\mathrm{q}_{\mathrm{t}}\right)$ versus $t$ showed the applicability of this kinetic model. The pseudo-first-order rate constant $\left(\mathrm{k}_{\mathrm{f}}\right)$ and $\mathrm{q}_{\mathrm{e}}$ values can be determined from the slope and intercept of the plotted line.

The pseudo-second-order model [25] is expressed as:

$$
\frac{d q_{t}}{d_{t}}=k_{s}\left(q_{e}-q_{t}\right)^{2}
$$

where $k_{s}(\mathrm{~g} /(\mathrm{mg} \cdot \mathrm{min}))$ is the rate constant of the pseudo-second-order sorption. The linear forms of equation (3) may be presented as follow [26, 27]:

$$
\frac{t}{q_{t}}=\frac{1}{k_{s} q_{e}^{2}}+\frac{1}{q_{e}} t
$$

According to equation (4), plotting $t / q_{t}$ versus $t$ gives a straight line with a slope of $1 /\left(\mathrm{k}_{\mathrm{s}} \mathrm{q}_{\mathrm{e}}{ }^{2}\right)$ and an intercept of $1 / \mathrm{q}_{\mathrm{e}}$.

Weber and Morris developed a widely accepted kinetic-based model that represents the time dependent intra-particle diffusion of components. Their model showed that the sorption process is diffusion-controlled if the rate is dependent upon the rate at which adsorbate and adsorbent diffuse toward one another [28]. The adsorbate uptake varies almost proportionally with $t^{1 / 2}$ rather than with the contact time, $t$. According to the following Weber-Morris's equation:

$$
q_{t}=k_{i} t^{1 / 2}+C
$$

where $C(\mathrm{mg} / \mathrm{g})$ is the intercept, and $k_{i}$ is the intra-particle diffusion rate constant $\left(\mathrm{mg} / \mathrm{g} \cdot \mathrm{min}^{1 / 2}\right)$, which can be calculated from the slope of the linear plots of $q_{t}$ versus $t^{1 / 2}$. A kinetic equation of chemisorption was established by Zeldowitsch [29] and was used to describe the rate of adsorption of carbon monoxide on manganese dioxide that decreases exponentially with an increase in the amount of gas adsorbed [27], which is the so-called Elovich equation as follows [30]:

$$
d q_{t} / d_{t}=\alpha_{\text {exp }}\left(-\beta q^{2}\right)
$$

where $\alpha$ is the initial adsorption rate $(\mathrm{mg} / \mathrm{g} \cdot \mathrm{min})$, and $\beta$ is the adsorption constant $(\mathrm{g} / \mathrm{mg})$ during any experiment. With the assumption of $\alpha \beta>>1$, equation (6) was integrated by using the boundary conditions of $q=0$ at $t=0$ and $\mathrm{q}=\mathrm{q}$ at $\mathrm{t}=\mathrm{t}$ to yield:

$$
q_{t}=1 / \beta \ln (\alpha \beta)+1 / \beta \ln (t)
$$


If ammonium ion adsorption fits the Elovich model, a plot of $q_{t}$ versus $\log t$ should yield a linear relationship with a slope of $1 / \beta$ and an intercept of $1 / \beta \log (\alpha \beta)$. Kinetic parameters of ammonium ion adsorption onto MWCNTs initial ion concentrations are shown in Table 1. The results obtained indicate that only the pseudo-second order model fit the kinetic data for MWCNTs on ammonium ions in the whole data range. Furthermore, the values of $R^{2}$ and ARE for the pseudo-second-order model are much higher than other kinetic models. There was good agreement between the model fit and experimentally observed equilibrium adsorption capacities in addition to the large correlation coefficients. This suggests that ammonium ion adsorption onto MWCNTs followed the pseudo-second-order kinetic model.

Table 1. Comparison of kinetic models for adsorption of ammonium ion.

\begin{tabular}{lll}
\hline Model & Parameters & Value \\
\hline Pseudo-first-order & $\mathrm{q}_{\mathrm{e}} \exp (\mathrm{mg} / \mathrm{g})$ & 95.74 \\
& $\mathrm{qe}_{\mathrm{e}} \mathrm{cal}(\mathrm{mg} / \mathrm{g})$ & 41.21 \\
& $\mathrm{~K}_{\mathrm{f}}\left(\mathrm{min}^{-1}\right)$ & 0.121 \\
& $\mathrm{R}^{2}$ & 0.875 \\
Pseudo-second-order & $\mathrm{ARE}$ & 3.90 \\
& $\mathrm{q}_{\mathrm{e}}$ exp $(\mathrm{mg} / \mathrm{g})$ & 97.92 \\
& $\mathrm{qe}_{\mathrm{e}} \mathrm{cal}(\mathrm{mg} / \mathrm{g})$ & 98.1 \\
& $\mathrm{~K}_{\mathrm{s}}(\mathrm{g} / \mathrm{mg} \cdot \mathrm{min})$ & 0.0071 \\
& $\mathbf{R}^{2}$ & $\mathbf{0 . 9 9 9}$ \\
Intra-particle diffusion & $\mathrm{ARE}$ & $\mathbf{1 . 1}$ \\
& $\mathrm{K}_{\mathrm{i}}\left(\mathrm{mg} / \mathrm{g} / \mathrm{min}^{1 / 2}\right)$ & 0.1352 \\
& $\mathrm{C}(\mathrm{mg} / \mathrm{g})$ & 0.0181 \\
& $\mathrm{R}^{2}$ & 0.988 \\
Elovich & $\mathrm{ARE}$ & 3.2 \\
& $\alpha$ & 0.4489 \\
& $\beta$ & 10.1351 \\
& $\mathrm{R}^{2}$ & 0.895 \\
& $\mathrm{ARE}$ & 0.7 \\
\hline
\end{tabular}

Adsorption isotherms are essential for the description of the interactive behaviour between adsorbate and adsorbent, and they are critical in optimizing the application of an adsorbent. To estimate adsorption capacities, the equilibrium data was fitted to the well-known Langmuir and Freundlich isotherm models [31]. The mathematical representations of these models are given in the equations below ((8) and (9), respectively): 


$$
\begin{aligned}
& \frac{1}{Q_{e}}=\frac{1}{Q_{O}}+\left(\frac{1}{Q_{O} K_{L}}\right) \frac{1}{C_{e}} \\
& \log Q_{e}=\log K_{f}+\frac{1}{2.303 n} \log C_{e}
\end{aligned}
$$

where, $Q_{e}$ is the adsorbate equilibrium amount in solid phases $(\mathrm{mg} / \mathrm{g}), Q_{0}$ is the maximum adsorption capacity according to Langmuir monolayer adsorption $(\mathrm{mg} / \mathrm{g})$, and $K_{L}$ is constant according to the Langmuir isotherm $(\mathrm{L} / \mathrm{mg}) . K_{F}(\mathrm{mg} / \mathrm{g})(\mathrm{L} / \mathrm{mg})$ and $n$ are Freundlich constants related to adsorption capacity and adsorption intensity of the adsorbent, respectively. The values of $K_{F}$ and $1 / n$ can be obtained from the intercept and slope, respectively, of the linear plot of experimental data of $\log Q_{e}$ versus $\log C_{e} .1 / n$ values indicate the type of isotherm to be irreversible $(1 / n=0)$, favorable $(0<1 / n<1)$ and unfavorable $(1 / n>1)$ [20]. Langmuir isotherm values of $Q_{0}$ and $K_{L}$ can be calculated from the slope and intercept of the linear plot of $1 / Q_{e}$ versus $1 / C_{e}$. The adsorption isotherm for ammonium ions by MWCNTs surface is listed in Table 2.

Table 2. Fitting parameters of the ammonium ions adsorption experimental results to the Langmuir and Freundlich isotherm models.

\begin{tabular}{lll}
\hline Model & Parameter & Value \\
\hline \multirow{3}{*}{ Langmuir } & $\mathrm{Q}_{0}(\mathrm{mg} / \mathrm{g})$ & 129 \\
& $\mathrm{~K}_{\mathrm{L}}(\mathrm{L} / \mathrm{mg})$ & 3.08 \\
& $\mathbf{R}^{2}$ & $\mathbf{0 . 9 9 9}$ \\
Freundlich & $1 / \mathrm{n}$ & 0.802 \\
& $\mathrm{~K}_{\mathrm{F}}(\mathrm{mg} / \mathrm{g})(\mathrm{L} / \mathrm{mg})$ & 41.3 \\
& $\mathrm{R}^{2}$ & 0.852 \\
\hline
\end{tabular}

Based on the correlation coefficient as shown in Table 2, isotherm Langmuir represents a better fit of experimental data than Freundlich isotherm in all cases. It indicates that the surfaces of adsorbents are mainly made up of heterogeneous adsorption patches [24] in addition to less homogeneous patches [32]. The Freundlich constant ( $n$ ) is a measure of adsorption intensity. As seen from Table 2, the values of $1 / n$ for adsorbent were below 1 , which indicate high adsorption intensity [25]. $\mathrm{K}_{\mathrm{F}}$, which is related to the adsorption capacity, also shows that the adsorption capacity increased with temperature increase, indicating that the adsorption processes are exothermic in nature. But the increase of the values of $1 / n$ with the temperature decrease suggests the 
increasing trend of the adsorption intensity. As temperature increased, the more ammonium ions were adsorbed, the keener the competitions for the limited adsorption sites and the stronger the attraction among the molecules, which resulted in an increase of adsorption intensity. From the results, MWCNTs surface has advantages for adsorption of ammonium ions. The favorability of the ammonium ion adsorption process onto adsorbent surfaces evaluated using a dimensionless parameter $\left(R_{L}\right)$ derived from the Langmuir expression is defined as follows [33]:

$$
R_{L}=\frac{1}{1+K_{L} C_{O}}
$$

The adsorption process can be defined as irreversible $\left(R_{L}=0\right)$, favorable $\left(0<R_{L}<1\right)$, linear $\left(\mathrm{R}_{\mathrm{L}}=1\right)$ or unfavorable $\left(\mathrm{R}_{\mathrm{L}}>1\right)$ in terms of $R_{\mathrm{L}}$ [30]. The calculated values of $R_{L}$ for adsorption of ammonium ions by MWCNTs surface fall between 0 and 1 ; thus, the adsorption of ammonium onto adsorbent is favorable. The adsorption capacity of the MWCNTs, calculated by the Langmuir equation, was about $129 \mathrm{mg} / \mathrm{g}$. In addition, the removal efficiency for adsorbate was found to be $95 \%$.

\section{CONCLUSIONS}

In this study, multi-walled carbon nanotubes (MWCNTs) were tested as adsorbent for the removal of ammonium ions. The effect of contact time, temperature and initial ions concentration on the removal of ammonium ions was investigated through batch experiments. The optimum contact time, temperature and initial concentration for adsorption were obtained to be $60 \mathrm{~min}$, $338 \mathrm{~K}$ and $140 \mathrm{mg} / \mathrm{L}$, respectively. The kinetics of adsorbent was experimentally studied and the obtained rate data were analysed using the pseudo-firstorder, pseudo-second-order, intra-particle diffusion, and Elovich models. Based on the values of the correlation coefficient $\left(R^{2}\right)$ and average relative error (ARE) obtained for all tested models, pseudo-second-order was found to best correlate the rate kinetic data of MWCNTs. In addition, adsorption parameters for the Langmuir and Freundlich isotherms were determined and the equilibrium data were found to be best described by the Langmuir isotherm model with maximum adsorption capacity of $129 \mathrm{mg} / \mathrm{g}$. Moreover, the removal efficiency for adsorbate respectively was found to be $95 \%$. Therefore, MWCNTs could be considered as a promising absorbent for water treatment or environmental management in terms of high efficiency and feasibility. 


\section{EXPERIMENTAL SECTION}

MWCNTs were purchased from Nano Amor Nanostructured \& Amorphous Materials, Inc., USA (Purity, > 95\%; outer > $50 \mathrm{~nm}$; length, 500-115 $2000 \mathrm{~nm}$; surface area, $\sim 40 \mathrm{~m}^{2} / \mathrm{g}$; and the manufacturing method, catalytic chemical vapour deposition (CVD)). Ammonium chloride salt $\left(\mathrm{NH}_{4} \mathrm{Cl}\right)$ (molecular weight, $53.16 \mathrm{~g} / \mathrm{mol}$ ) was supplied by Merck (Germany) (maximum purity available). Doubly distilled deionized water (HPLC grade $99.99 \%$ purity) was obtained from Sigma Aldrich Co. (Germany). All supplementary chemicals were of analytical grades and were purchased from Merck Inc., USA.

The functional groups of the prepared materials were identified by Fourier transform infrared spectroscopy (FTIR) using a Tensor 27, Bruker, Germany. Small portions (about $5 \mathrm{mg}$ ) of powder samples were homogenized with $\mathrm{KBr}$ (about $100 \mathrm{mg}$ ) using an agate mortar and pelletized prior to measurement. Moreover, the surface morphology of MWCNTs was investigated with a JEOL JSM-5900LV scanning electron microscope (SEM) (Japan) with an acceleration voltage of $20 \mathrm{KV}$.

For the purpose of studying the adsorption process, a $1000 \mathrm{mg} / \mathrm{L}$ stock solution of ammonium was prepared by dissolving $3.819 \mathrm{~g}$ of ammonium chloride $\left(\mathrm{NH}_{4} \mathrm{Cl}\right)$ in deionized water. The solutions to be used were prepared by diluting the stock solution with deionized water when necessary.

Adsorption experiments were conducted by using $100 \mathrm{~mL}$ glass flask containing $0.05 \mathrm{~g}$ of the adsorbent and $10 \mathrm{~mL}$ of the ammonium ions solution with the initial concentration of $140 \mathrm{mg} / \mathrm{L}$. The glass flask was sealed with a glass stopper. The samples were then mounted on an ultrasonic bath for $60 \mathrm{~min}$ at various temperatures (298 - $328 \mathrm{~K})$. The ultrasonic bath (71020-DTH-E; Model 1510 DTH, 220V; EMS Company) was used to prevent particles aggregation and bulk formation. Then, the samples were centrifuged at $4500 \mathrm{rpm}$ and the supernatant was filtered by $0.2 \mu \mathrm{m}$ filter paper for subsequent ammonium concentration analysis. The initial and final ammonium concentrations remaining in solutions were analysed by a UV spectrophotometer (Varian-Cary100 Bio), monitoring the absorbance changes at a wavelength of maximum absorbance $(\lambda=400 \mathrm{~nm})$. The difference between the initial and equilibrium ion concentrations could determine the amount of ions adsorbed onto the MWCNTs surface. The amount of ammonium adsorbed was determined by the difference between the initial and residual concentration of ammonium ion solution. The removal capacity of ammonium ions by MWCNTs was calculated using the equations (11) and (12), respectively [34, 36]: 


$$
\begin{aligned}
& q_{e}=\frac{\left(C_{o}-C_{e}\right) V}{m} \\
& \text { Removal }(\%)=100 \times \frac{\left(C_{o}-C_{e}\right)}{C_{o}}
\end{aligned}
$$

where $q_{e}$ was the amount of ammonium ions taken up by the MWCNTs $(\mathrm{mg} / \mathrm{g}), C_{o}$ was the initial ammonium ions concentration put in contact with the MWCNTs (mg/L), $C_{e}$ is the ammonium ions concentration $(\mathrm{mg} / \mathrm{L})$ after the adsorption procedure, $m$ is MWCNTs mass $(\mathrm{g})$ and $V$ is the volume of the ammonium ions solution ( $L$ ). To evaluate the fitness of kinetic and isotherm equations to the experimental data, ARE was calculated using equation (13) and used to measure the kinetic and isotherm constants [37]. ARE can be expressed as:

$$
\operatorname{ARE}(\%)=\frac{100}{n} \sum_{i}^{n}\left|\frac{q_{i, \text { cal }}-q_{i, \text { exp }}}{q_{i, \text { exp }}}\right|
$$

where $n$ is the number of data points. Each experiment was conducted in triplicate under in the same conditions to confirm the results, and was found reproducible. Also, all the experiments were performed in triplicate, and only the mean values have been reported. Ammonium ions concentration was measured by Nesslerization Method [38].

\section{ACKNOWLEDGMENTS}

The authors would like to thank Islamic Azad University Science and Research Branch for all supports.

\section{REFERENCES}

1. K. Zare, H. Sadegh, R. Shahryari-Ghoshekandi, M. Asif, I. Tyagi, S. Agarwal, V.K. Gupta, Journal of Molecular Liquids, 2016, 213, 345.

2. V. K. Gupta, H. Sadegh, M. Yari, R. Shahryari Ghoshekandi, B. Maazinejad, M. Chahardori, Global Journal of Environmental Science and Management, 2015, $1,149$.

3. H. Sadegh, R. Shahryari-Ghoshekandi, A. Masjedi, Z. Mahmoodi, M. Kazemi, International Journal of Nano Dimension, 2016, 7, 109. 
4. V.K. Thakur, M.K. Thakur, Chemical Functionalization of Carbon Nanomaterials: Chemistry and Applications, CRC Press, USA, 2015, chapter 30.

5. V.K. Gupta, I. Tyagi, H. Sadegh, R. Shahryari-Ghoshekandi, A.S.H. Makhlouf, B. Maazinejad, Science, Technology and Development, 2015, 34, 195.

6. H. Sadegh, G.A.M. Ali, V.K. Gupta, A.S.H. Makhlouf, R. Shahryari-Ghoshekandi, M.N. Nadagouda, M. Sillanpää, E. Megiel, Journal of Nanostructure in Chemistry, 2017, 7(1), 1.

7. H.H. Abdel Ghafar, G.A.M. Ali, O.A. Fouad, S.A. Makhlouf, Desalination and Water Treatment, 2015, 53(11), 2980.

8. S. lijima, Nature, 1991, 354, 56.

9. H. Sadegh, R. Shahryari-Ghoshekandi, M. Kazemi, International Nano Letters, 2014, 4, 129.

10. K. Zare, F. Najafi, H. Sadegh, Journal of Nanostructure in Chemistry, 2013, 3, 1.

11. K. Zare, H. Sadegh, R. Shahryari-Ghoshekandi, B. Maazinejad, V. Ali, I. Tyagi, S. Agarwal, V.K. Gupta, Journal of Molecular Liquids, 2015, 212, 266.

12. H. Sadegh, K. Zare, B. Maazinejad, R. Shahryari-Ghoshekandi, I. Tyagi, S. Agarwal, V.K. Gupta, Journal of Molecular Liquids, 2016, 215, 221.

13. H. Sadegh, R. Shahryari-Ghoshekandi, Nanomedicine Journal, 2015, 2, 231.

14. V.K. Gupta, O. Moradi, I. Tyagi, S. Agarwal, H. Sadegh, R. ShahryariGhoshekandi, A.S.H. Makhlouf, M. Goodarzi, A. Garshasbi, Critical Reviews in Environmental Science and Technology, 2016, 46, 93.

15. S. Soni, A. Salhotra, M. Suar, Handbook of Research on Diverse Applications of Nanotechnology in Biomedicine, Chemistry, and Engineering, IGI-Global, Hershey PA, 2015, chapter 6.

16. M. Rajabi, B. Mirza, K. Mahanpoor, M. Mirjalili, F. Najafi, O. Moradi, H. Sadegh, R. Shahryari-Ghoshekandi, M. Asif, I. Tyagi, S. Agarwal, V.K. Gupta, Journal of Industrial and Engineering Chemistry, 2016, 34, 130.

17. B. Pan, B. Xing, Environmental Science \& Technology, 2008, 42, 9005.

18. K. Zare, V.K. Gupta, O. Moradi, A.S.H. Makhlouf, M. Sillanpää, M.N. Nadagouda, H. Sadegh, R. Shahryari-Ghoshekandi, A. Pal, Z. Wang, I. Tyagi, M. Kazemi, Journal of Nanostructure in Chemistry, 2015, 5, 227.

19. N.B.A. Mansor, J.-P. Tessonnier, A. Rinaldi, S. Reiche, M.G. Kutty, Sains Malaysiana, 2012, 41(5), 603.

20. H. Sadegh, R. Shahryari-Ghoshekandia, I. Tyagib, S. Agarwalb, V.K. Gupta, Journal of Molecular Liquids, 2015, 207, 21.

21. X. Cheng, J. Zhong, J. Meng, M. Yang, F. Jia, Z. Xu, H. Kong, H. Xu, Journal of Nanomaterials, 2011, 2011, doi.org/10.1155/2011/938491.

22. R. Wahab, S.T. Khan, J. Ahmad, S.G. Ansaric, J. Musarrat, A.A. Al-Khedhairy, Vacuum, 2017, http://dx.doi.org/10.1016/j.vacuum.2017.01.022.

23. S. Agarwal, H. Sadegh, M. Monajjemi, A.S. Hamdy, G.A.M. Ali, A.O.H. Memar, R. Shahryari-Ghoshekandi, I. Tyagi, V.K. Gupta, Journal of Molecular Liquids, 2016, 218, 191.

24. N. Gupta, A.K. Kushwaha, M.C. Chattopadhyaya, Journal of the Taiwan Institute of Chemical Engineers, 2012, 43(1), 125. 
25. V. Mishra, C. Balomajumder, V.K. Agarwal, CLEAN-Soil, Air, Water, 2012, 40, 718.

26. Y.-S. Ho, Journal of Hazardous Materials, 2006, 136, 681.

27. Y.-S. Ho, G. McKay, Process Biochemistry, 1999, 34, 451.

28. H. Fan, J. Yang, T. Gao, H. Yuan, Journal of the Taiwan Institute of Chemical Engineers, 2012, 43, 386.

29. J. Zeldowitsch, Acta Physicochim URSS, 1934, 1, 364.

30. M.J.D. Low, Chemical Reviews, 1960, 60, 267.

31. O. Moradi, H. Sadegh, R. Shahryari-Ghoshekandi, Adsorption and desorption in carbon nanotubes, discovery and evolution, LAP LAMBERT Academic Publishing, 2014.

32. H. Sadegh, R. Shahryari-Ghoshekandi, S. Agarwal, I. Tyagi, M. Asif, V.K. Gupta, Journal of Molecular Liquids, 2015, 206, 151.

33. O.A. Habeeb, K. Ramesh, G.A.M. Ali, R.M. Yunus, T.K. Thanusha, O.A. Olalere, Australian Journal of Basic and Applied Sciences, 2016, 10(17) 136.

34. R. Sivaraj, C. Namasivayam, K. Kadirvelu, Waste Management, 2001, 21, 105.

35. V.K. Gupta, I. Tyagi, S. Agarwal, H. Sadegh, R. Shahryari-Ghoshekandi, M. Yari, O. Yousefi-Nejat, Journal of Molecular Liquids, 2015, 206, 129.

36. O. Moradi, V.K. Gupta, S. Agarwal, I. Tyagi, M. Asif, A.S.H. Makhlouf, H. Sadegh, R. Shahryari-Ghoshekandi, Journal of Industrial and Engineering Chemistry, 2015, 28, 294.

37. R. Shahryari-Ghoshekandi, H. Sadegh, Jordan Journal of Chemistry, 2014, 9, 267.

38. APHA, AWWA, and WEF (American Public Health Association, American Water Works Association, and Water Environment Federation), Standard Methods for the Examination of Water and Wastewater, 20th ed. APHA, Washington, DC, 1998. 
